\title{
Exploring and Evaluating "TaPrEC+mBot” Environment with Preschool Children
}

\author{
Marleny Luque Carbajal ${ }^{1}$, M. Cecília C. Baranauskas ${ }^{1}$ \\ ${ }^{1}$ Institute of Computing - University of Campinas (UNICAMP) \\ Post Office Box 6.176 - 13.083-970 - Campinas - SP - Brazil
}

\begin{abstract}
Contact with programming has a positive impact on the development of cognitive and socio-emotional skills in children. However, programming can be a challenging activity for young children. Many studies suggest that tangible environments can engage children to explore basic programming concepts more easily. In this paper, we present results obtained during a Case Study conducted to introduce preschool children into programming through TaPrEC $+m B o t$, an environment that allows to program a robot car by arranging wooden programming blocks. The results suggest that our environment is attractive and interesting for young children, although it still needs to adjust labeling programming blocks to facilitate their learning in early childhood settings.
\end{abstract}

\section{Introduction}

The research of [Bers 2008] has shown that children could build robotics projects and understand some basic programming concepts when they are as young as four years old. When programming, children explore concepts of sequencing, patter recognition, and cause-and-effect relationships that are already represented in Kindergarten curricula when children learn how to tell a story from beginning to end, sequence numbers and letters, and order objects by size, shape, or color [Kazakoff et al. 2013]. A potentially facilitated way to introduce young children to programming is by Tangible User Interfaces (TUIs) [Ishii and Ullmer 1997] because they allow children to write programs by simply assembling physical objects [Horn et al. 2012]. The approach of TUIs proposes to embed computing elements in concrete materials, creating an educational feature that unites the advantages of physical interaction and multimedia handling provided by technology. Beside that, TUIs leverage children's natural kinesthetic learning strategies to make abstract concepts accesible and intuitive [Xu 2005].

Educational robotics kits have become a new generation of learning manipulatives that help children develop a stronger understanding of mathematical concepts in much the same way that traditional materials do [Brosterman and Togashi 1997, Resnick et al. 1998]. Moreover, robotics and computer programming in early childhood education can support the development of a range of cognitive and social milestones [Bers 2012]. In this paper, we present and discuss results of a Case Study conducted in two preschool classrooms where we used TaPrEC+mBot [Carbajal and Baranauskas 2018], a tangible programming environment designed for children to learn basic programming concepts. The TaPrEC+mBot environment consists of four parts: hardware (notebook and RFID ${ }^{1}$ system), programming blocks, robot

\footnotetext{
${ }^{1}$ RFID: Radio Frequency IDentification
} 
car, and control software. Children can program the robot car by arranging programming blocks. The context is a workshop conducted by a group of computer science researchers to introduce young children in programming through creative and meaningful experiences. There are two questions explored in this Case Study: i) "Is TaPrEC+mBot environment easy to learn or to use by young children?", and ii) "Is $\operatorname{TaPrEC}+m B o t$ fun and attractive for young children?". This paper is organized as follows: in Section 2 we present related works with focus on environments where input and output are both tangible. In Section 3, we describe the TaPrEC+mBot environment and its functioning. Then, in Section 4, we present details of our Case Study conducted with twenty-eight children and two preschool teachers, and the results achieved. In Section 5, we present the discussion of results and findings to adjust the environment for children aged 4-5 years. Finally, we present our conclusions and future work in Section 6.

\section{Related Work}

This section illustrates some tangible programming tools designed for young children, that support the physical construction of a computer program by connecting or stacking parts that represent an action that is performed by a robot. Electronic Blocks [Wyeth and Purchase 2003] are physical Lego blocks that can be physically stacked and arranged to form computer programs that interact with the physical world as cars that move when a flashlight shines on them. There are three kinds of blocks: sensor blocks, logic blocks, and action blocks. Dr. Wagon [Chawla et al. 2013] is a tangible programming toy that includes a series of programming blocks and a wagon-shaped robot. The programming blocks include basic functions ("move"), conditions, and loops. These blocks can be connected in various ways to control the behavior of the wagon. KIBO [Sullivan et al. 2015] allows young children aged 4-7 to program the robots' actions with tangible programming blocks, during which they can explore sequences, loops, and variables.

The programming environments described above vary with respect to the programming concepts, tangible objects, and technology embedded in them. They have advantages in conveying a broad range of programming concepts, but they require children to have some skills and understanding of programming. In this work, we tried to simplify the programming environment and focus on the concepts of sequence and programming blocks of movements that could help to develop young children's spatial skills. These skills are linked to children's participation in STEAM fields (science, technology, engineering, arts, and mathematics) later in life [Uttal et al. 2013, Verdine et al. 2014].

\section{TaPrEC+mBot: An environment with input and output both tangible}

TaPrEC $+m B$ ot [Carbajal and Baranauskas 2018] is a tangible programming environment designed to provide children with an engaging introduction to computer programming. They should be able to build physical computer programs by organizing tangible objects and applying basic programming concepts such as sequence, repetition, procedures. It is consists of four parts (see Figure 1 left): i) hardware: notebook and RFID system (tag and reader), ii) programming blocks which is a set of colored pieces of puzzle-like wooden blocks containing an RFID tag on one side and an embossed symbol on the other, iii) $\mathrm{mBot}^{2}$, a robot car that we used to represent the physical output of tangible programs

\footnotetext{
${ }^{2}$ https://www.makeblock.com/steam-kits/mbot
} 
VIII Congresso Brasileiro de Informática na Educação (CBIE 2019)

Anais do XXV Workshop de Informática na Escola (WIE 2019)

and iv) software: a control program that we developed in the mBlock ${ }^{3}$, a Scratch-based programming software tool, to allow communication via Bluetooth between the programming blocks and the mBot.
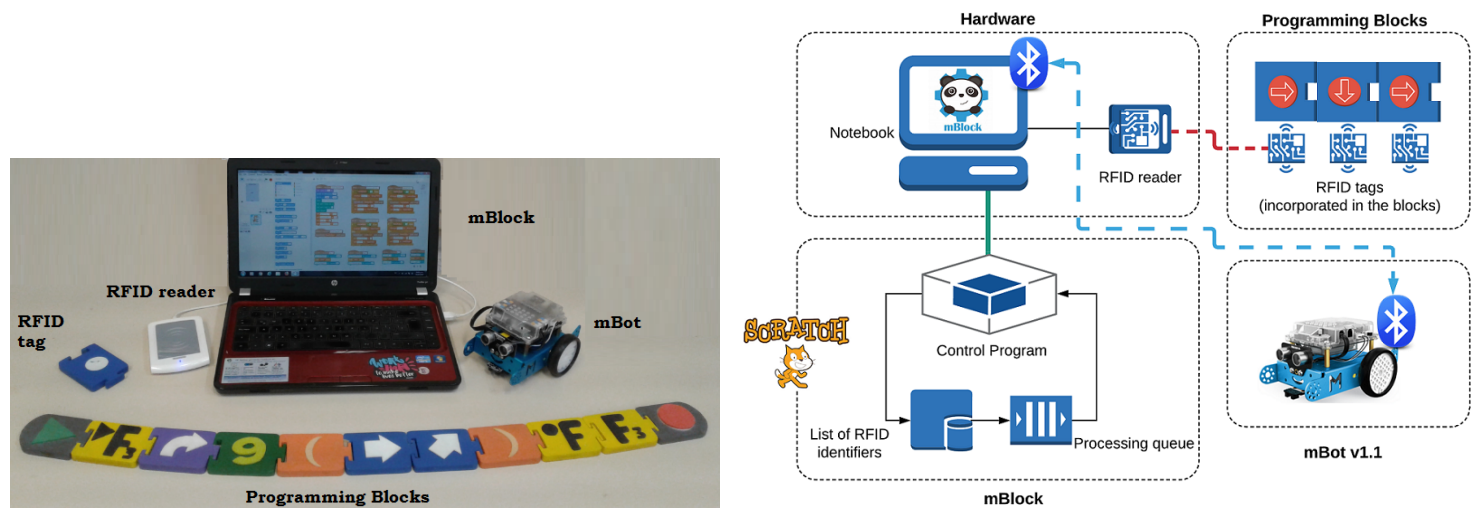

Figure 1. TaPrEC+mBot physical environment (left), system architecture (right)

Through the RFID reader, the tangible program information is entered into the TaPrEC $+m B$ ot environment. When the user passes the RFID reader over each programming block, the identifiers of the RFID tags are sent to the control program. The control program verifies if they exist in the list of RFID identifiers, and it sends them to the processing queue. Then, the control program sends to $\mathrm{mBot}$, via Bluetooth, the Scratch commands associated with each RFID identifier (see Figure 1 right). Finally, mBot executes the sequence of commands received in the physical world.

\section{Case Study}

The settings for the study was the Children Living Center (CECI - Portuguese acronym of Centro de Convivência Infantil). Located on the campus of the University of Campinas (UNICAMP), it is a space that gives access to the education of infants and children from six months to six years old. Furthermore, our study is part of a project approved by the university's research ethics committee under the number 72413817.3.0000.5404. For this study, we worked with two preschool class (one class of the morning and one class of the afternoon). The first class was composed of fourteen children ( 9 boys and 5 girls) aged four to five with a mean age of $5.25\left(\mathrm{SD}^{4}=0.27\right)$. The second class had fourteen children ( 7 boys and 7 girls) aged four to five with a mean age of $5.18(\mathrm{SD}=0.41)$. We held a workshop with each class that lasted 90 minutes. The workshops were documented by video and photos.

Before the children's workshops, we conducted a pilot work with the teachers so that they could have their own experience with the TaPrEC+mBot environment. With the help of the teachers, we devised the activity to children's workshops: the children had to program the robot car to enter into a garage (a little paper house on the floor). The idea of the teachers was that "the children's first contact should be to explore the material, and see how the robot moves". During the pilot work, we suggested to use only the movement and rotation programming blocks to reduce the complexity of the

\footnotetext{
${ }^{3}$ https://www.mblock.cc/en-us/

${ }^{4}$ SD: Standard Deviation
} 
VIII Congresso Brasileiro de Informática na Educação (CBIE 2019)

Anais do XXV Workshop de Informática na Escola (WIE 2019)

environment. The teachers agreed and they suggested to use the following programming blocks: forward, backward, turn left, and turn right (see Figure 2 left). In the children's workshop, we began by presenting the whole environment and introducing the use of programming blocks to children. We explained to the children that to create a tangible program it is necessary to organize the programming blocks in a specific sequence: first the "start block", then the blocks of movement, and finally the "end block". With each class, we demonstrated the functioning of each movement block with simple tangible programs. After the demonstration, we explained the activity and each class began to create tangible programs. The teachers were present and involved during the workshop. As suggestion of the teachers, the children were organized in pairs, so that while one pair interacted with the TaPrEC $+m B o t$, the other children were around observing or giving suggestions (see Figure 2 right).

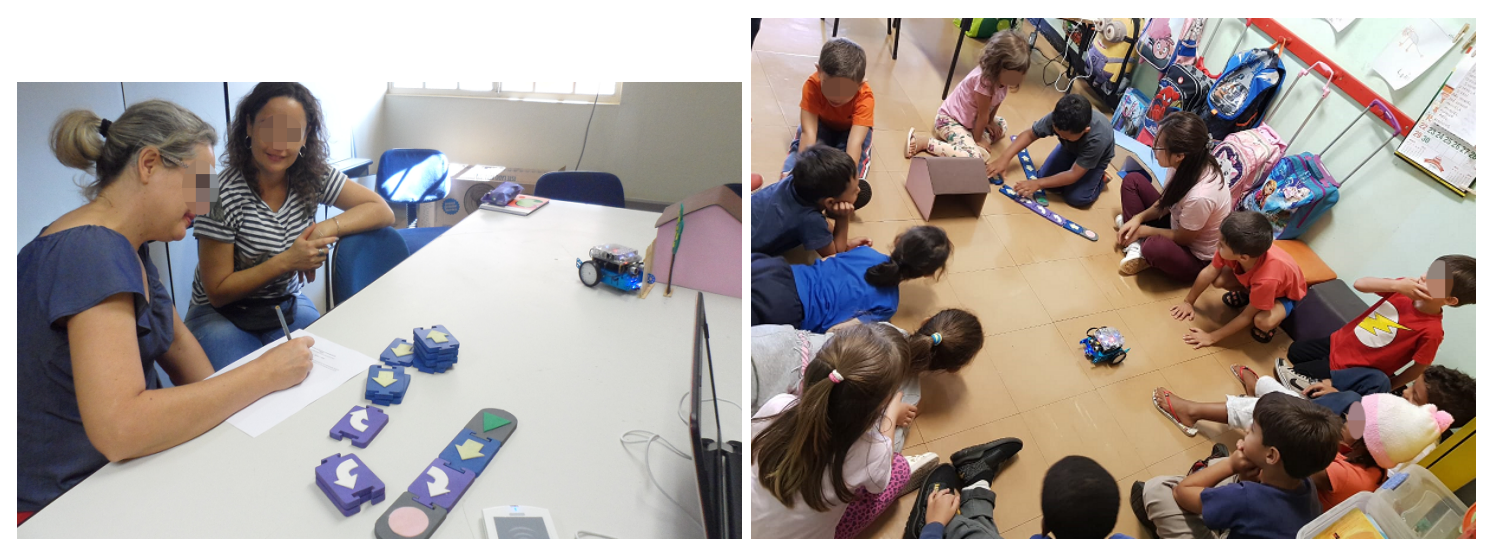

Figure 2. Pilot work with the teachers (left) and a team of children programming the mBot (right)

We finished the workshop by applying the Emoti-SAM adapted according to the teachers' suggestions. The Emoti-SAM [Hayashi et al. 2016] consists of 15 emoticons, representing the three dimensions of affective responses: pleasure, arousal, and dominance. Each line represents a dimension that varies in a 5-point scale, from the most positive to the most negative, or the opposite, for the dominance dimension (see Figure 3 left). For the pleasure dimension (first line), the most positive option is a happy face with the thumb up and, in opposition, the most negative was an angry face with the thumb down. The most positive option for the arousal dimension (second line) is a happy face with hearts and a light bulb around it, representing good feelings and ideas, respectively; the most negative option is a face with its eyes closed and with letters "Z" above it, representing it is sleeping. For the dominance dimension (third line), the authors associated the sensation of being in control with the feeling of being very intelligent and it is represented by the emoticon with the graduation hat; and the extreme opposite is represented by a face of disappointment.

During the pilot work with the teachers, we suggested to use only the pleasure dimension to simplify the evaluation by the children. The teachers agreed because they believe that emoticons are an appropriate assessment due to the familiarity that children have with those images. However, the teachers suggested to change the last image of pleasure dimension by the first image of the dominance dimension because they believed the last pleasure emoticon was too negative. Also, they suggested to add a blank space so that 
VIII Congresso Brasileiro de Informática na Educação (CBIE 2019)

Anais do XXV Workshop de Informática na Escola (WIE 2019)

the children could freely express their feelings about the workshop through their drawing too (see Figure 3 right). As a child-centered evaluation tool, drawings can be advantageous as they are fun and attractive universal activities [Xu et al. 2009], easily produced by children who either may not be able to write proficiently (if at all) or may feel unsure of expressing themselves verbally to a researcher. Drawing may also capture some of the experience of the user in a way that not be easily expressed in words [Xu et al. 2009].

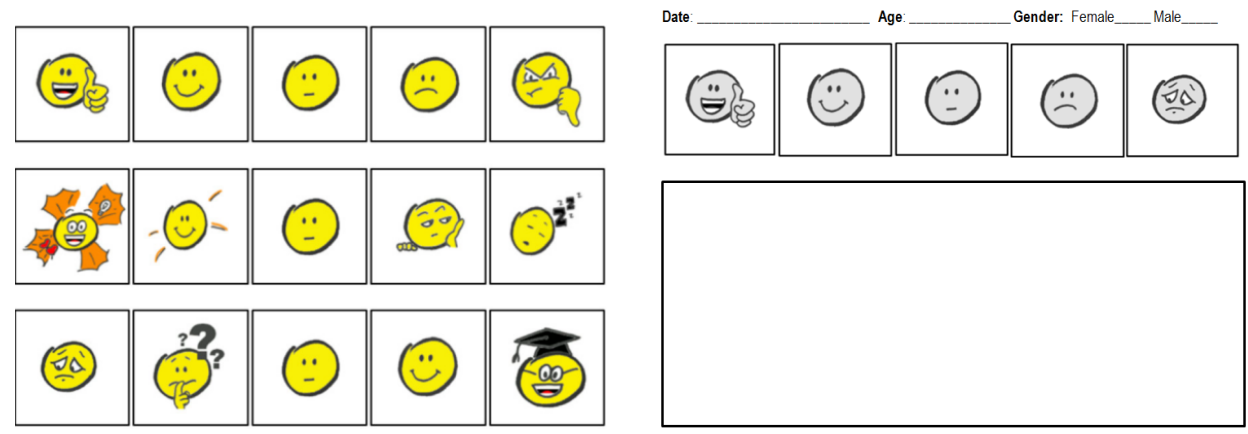

Figure 3. Emoti-SAM [Hayashi et al. 2016](left) and Emoti-SAM adapted by the teachers translated from Portuguese (right)

\section{Results}

In the following sections, we show the main results of our case study: i) the behavior of the children while interacting with the TaPrEC $+m B o t$ environment, ii) the process of tangible programs creation, iii) the feedback from the Emoti-SAM adapted instrument and the drawings of children about the workshop. Regarding the children's behavior, we observed that at the beginning of the workshop, when the researcher showed the programming blocks and the mBot, some children already imagined how our environment works. For example, one girl said: "Do these little pieces control the robot?" One boy said: "The pieces are placed one in the other" Other boy said: "This piece is for speed". At the time the researcher moved the robot through tangible programs, the children were excited and said: "The robot moved!", "It's cool!", "It's amazing!", "The robot dance, the robot dance". They moved their bodies imitating the movements of the robot. For example, when the robot turn left or turn right, the children turned their bodies accordingly. Teachers participated by managing the interaction time of each team and behavioral issues during the workshop. For example, if any child was distracted, the teachers helped to attract his/her attention with phrases like: "Now, where will the robot go?", "Pay attention, the robot will turn now!". The children observed the tangible programs that the researcher created, and they tried to guess what would be the next movement of the robot: "Will the robot go back there?" (pointing another space of the room), "The robot will see him" (pointing to another child). Other children asked to experiment with combinations of programming blocks to see what happened. For example, one boy said: "What the robot will do if we place these two blocks together?".

Regarding the process of creating tangible programs, inspired by [Worsley and Blikstein 2013]'s work, the teams' videos were coded using a mark on each type of activity that the children did during the programming time. We used the following four types of programming activity: building a program with blocks (BUILD), passing the RFID reader over the tangible program and observing the mBot act out the 
VIII Congresso Brasileiro de Informática na Educação (CBIE 2019)

Anais do XXV Workshop de Informática na Escola (WIE 2019)

tangible program (TEST), undoing programming blocks to make a change to the tangible program (UNDO), thinking with or without an object (a programming block, the RFID reader) on the hand (THINK). Table 1 and Table 2 show the video coding of the morning class and the afternoon class, respectively. Each class had 7 teams of children.

Table 1. Video Coding of the Morning class

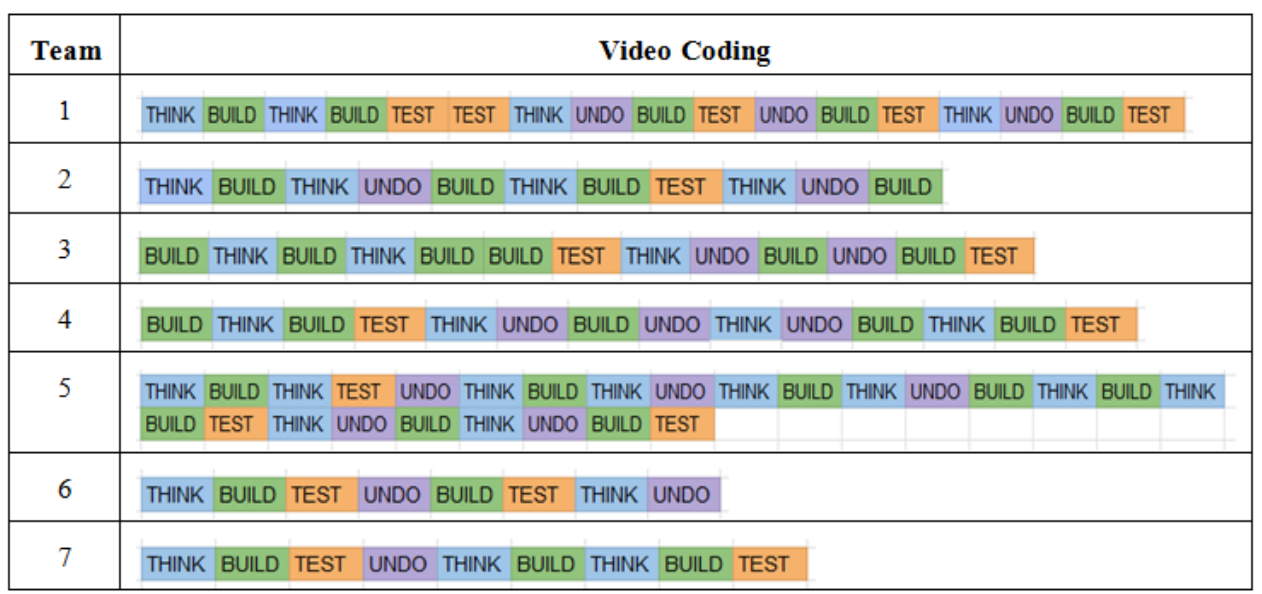

Table 2. Video Coding of the Afternoon class

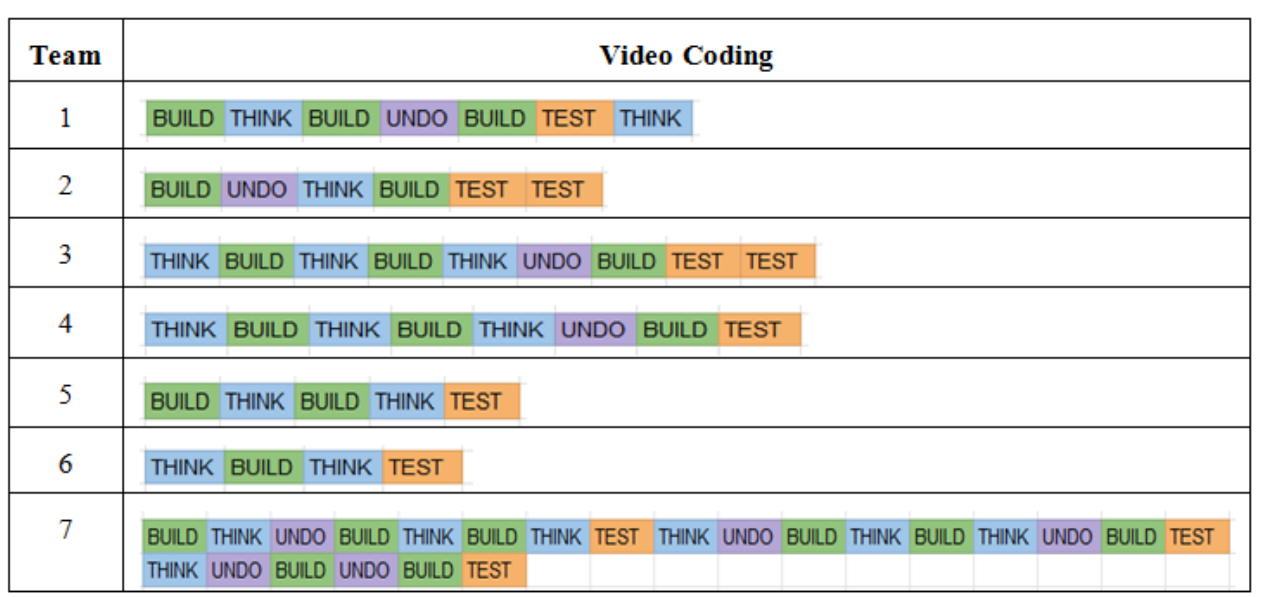

About the performance of the teams, we observed that some pairs set up the tangible program from right to left. That is, they started at the "end block" and ended at the "start block". At this moment, we reinforced the initial explanation about the correct sequence to set up a tangible program in the TaPrEC+mBot environment. These teams had to undo their tangible programs to correct them. This was registered in the video coding with the code UNDO in the team 2 of the morning class, and the teams 1 and 2 of the afternoon class. We observed that the children had difficulties to differentiate between the "forward" and "backward"; "turn left" and "turn right" programming blocks. This was registered in the video coding of the teams 1,2, and 3 of the morning class: before the first code TEST, the THINK codes correspond to the moments that they thought with the block in hand to discover if the block was, for example, "forward" or "backward". In the case of the afternoon class, this same situation was registered with THINK codes for teams 3 and 4. Another problem that the children had was to identify the front "face" 
VIII Congresso Brasileiro de Informática na Educação (CBIE 2019)

Anais do XXV Workshop de Informática na Escola (WIE 2019)

of the robot. A very important fact if we think that the front of the robot is the point of reference for the movements. This caused some confusion in the children, and they tested the same program again. This was registered in the video coding of the team 1 of the morning class, and teams 2 and 3 of the afternoon class. Only two of the fourteen teams were able to conduct the task thoroughly: team 1 of the morning class and team 7 of the afternoon class. Analyzing the video coding, we also discovered that the teams 3 and 4 of the morning class, and the teams 1,2,5, and 7 of the afternoon class, started the action sequence with the code BUILD. These teams started the task by directly building a tangible program without observing the position of the robot. They were very excited and wanted to watch the robot moving. On the other hand, the rest of the teams $(1,2,5,6$, and 7 of the morning class, and 3, 4, 6 of the afternoon class) started the actions sequence with the code THINK. They showed a more reflexive attitude, and before setting up the tangible program they thought of the movements for the robot to enter the garage. Some patterns that we identified through the video coding are i) the actions sequence THINK|BUILD appears at least 1 time in each team, ii) the actions sequence THINK|UNDO|BUILD appears in five teams of the morning class, and two teams of the afternoon class.

Regarding the adapted Emoti-SAM, Table 3 shows the responses of children. The children indicated, in a range of emoticons, their affective states about the workshop, painting the desired emoticon. Twenty of the twenty-eight children opted for the emoticon that represents the greatest happiness, two children opted for the second emoticon of the scale, and six children painted more than one emoticon, even some children painted all the emoticons. These last results were considered invalid for our evaluation. The results indicate that the activity was considered pleasurable and enjoyable for most of the children. To a correct analysis of the Emoti-SAM drawings, the children were asked individually what they had drawn. We quantified the drawings made by children (see Table 4). A sample of the Emoti-SAM drawings is illustrated in Figure 4.

Table 3. Emoti-SAM results from all children

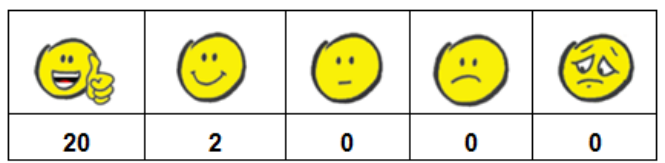

\section{Discussion}

To answer our first research question: "Is TaPrEC $+m B$ ot environment easy to learn or to use by young children?" We collected data regarding the process of creating a tangible program to discover possible problems in the understanding of the programming blocks. In order to analyze the process, we constructed a sequence of children's actions that are based on action codes. According to our observation, the main difficulty of the children was to differentiate the programming blocks with opposite movements. It was due to the fact of those blocks having similar symbols in appearance, shape, and color. Another difficulty of the children was to understand the structure of a tangible program. However, this difficulty happened only in the first teams of each class and disappeared along the workshop. When finalizing the workshop, most of the children seemed to understand the logical structure needed to create a tangible program (beginning, movements, end) and also that the blocks were to be connected in a sequence and interpreted from left to 
VIII Congresso Brasileiro de Informática na Educação (CBIE 2019)

Anais do XXV Workshop de Informática na Escola (WIE 2019)

Table 4. Emoti-SAM drawings collected of all children

\begin{tabular}{|c|c|}
\hline Type of drawing & Quantity \\
\hline robot & 17 \\
\hline garage (paper house) & 6 \\
\hline children in the class & 5 \\
\hline bridge & 4 \\
\hline programming blocks & 2 \\
\hline computer & 1 \\
\hline RFID reader & 3 \\
\hline school & 1 \\
\hline happy face & 3 \\
\hline himself/herself & 6 \\
\hline
\end{tabular}

right. We observed that the following teams learned from the mistakes of the first teams. This suggests that with some practice children could correctly use the TaPrEC+mBot environment.

For our second research question: "Is $\mathrm{TaPrEC}+m B$ ot fun and attractive for young children?" We were interested in collecting data about behavior, engagement, and emotions that children expressed during the workshop to evaluate if the programming activity proposed was fun for children. Regarding the children's behavior, during the activity, we observed that trying to control robots through programming was a very enthusiastic process for the children. Despite the initial difficulties, the verbal and bodily manifestations that we observed show that most children interacted with the environment with great freedom and enthusiasm. While building tangible programs, most of the children appeared enjoyable and engaged and showed strong interests and curiosities regarding the environment itself, especially the robot car and the Bluetooth communication between the car and programming blocks. Nevertheless, some teams were not concentrated on the task, they created the tangible programs to move the mBot, but they did not try to take the robot to the "garage". The younger children, who were much easier to be distracted by the playing objects in the scene, had more difficulties at the beginning. Regarding the children's emotions, we used Emoti-SAM adapted to allow children to express their opinions and feelings towards our tangible programming environment. Most of the children said they liked the environment very much in Emoti-SAM with an average score of 5.0, which was consistent with what we observed. The children made drawings symbolizing what they liked the most in the workshop. Seventeen of twenty-eight children drew the mBot; this may mean that the robot was in the center of attention for them. Some of the Emoti-SAM drawings represent a dynamic scene (for example, mBot crossing a bridge) that suggest a high level of involvement with the experience.

Based on the observations and results, we can highlight the following findings to improve the programming experience and programming blocks: i) when planning programming activities, the context of the children should be considered (for example, projects they are developing in regular classes) to create activities related to their interests; ii) allow children to suggest their activities; iii) change the color and/or shape of the opposite programming blocks to stress their differences and avoid confusion. 
VIII Congresso Brasileiro de Informática na Educação (CBIE 2019)

Anais do XXV Workshop de Informática na Escola (WIE 2019)

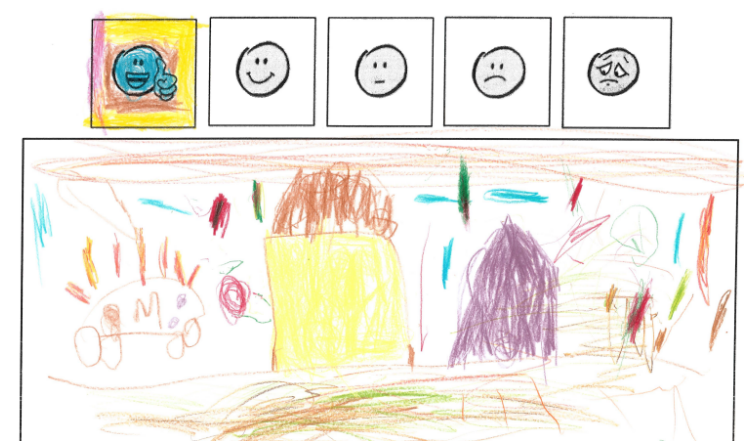

Figure 4. Emoti-Sam drawing. Child's explanation:'In this drawing there are the robot car, the house and our school"

\section{Conclusion}

TaPrEC $+m B o t$ is a technological environment designed with current educational challenges that highlight the development of computational training as an important skill child should develop to learn and hopefully appreciate science and technology later. The Case Study presented in the paper focused on children aged 4 to 5 years old, which is a critical period for developing spatial skills and establishing effective and long-lasting learning, to evaluate whether the $\operatorname{TaPrEC}+m B$ ot is appropriate for introducing young children into programming. The results suggest that $\mathrm{TaPrEC}+m B$ ot attracted the interest of most children and after some practice, it was easy to learn and easy to use. The findings suggest that $\operatorname{TaPrEC}+m B$ ot is an engaging environment that can encourage young children to explore introductory programming concepts. Further work in this research involves improving the labeling of programming blocks and exploring new ways to help children differentiate the symmetric actions, for example enriching the blocks with sounds.

\section{Acknowledge}

This study was financed in part by Coordenação de Aperfeiçoamento de Pessoal de Nivel Superior - Brasil (CAPES)- Finance Code 001 - scholarship \#1545149/2015 and \#1654045/2016, by the Nacional Council for Scientific and Technological Development - Brazil (CNPq) through grants \#140536/2019-1 and \#306272/2017-2, and by the São Paulo Research Foundation (FAPESP) through grant \#2015/16528-0. We would like to thank the Division of Child and Supplementary Education (DEdIC - Divisão de Educação Infantil e Complementar), the Children Living Center (CECI - Centro de Convivência Infantil) and Institute of Computing at University of Campinas

\section{References}

Bers, M. U. (2008). Blocks to robots: Learning with technology in the early childhood classroom. Teachers College Press New York, NY.

Bers, M. U. (2012). Designing digital experiences for positive youth development: From playpen to playground. Oxford University Press.

Brosterman, N. and Togashi, K. (1997). Inventing kindergarten. Harry N. Abrams.

Carbajal, M. and Baranauskas, M. C. (2018). Programação, robôs e aprendizagem criativa por meio de cenários: um estudo exploratório. In Brazilian Symposium on Comput- 
VIII Congresso Brasileiro de Informática na Educação (CBIE 2019)

Anais do XXV Workshop de Informática na Escola (WIE 2019)

ers in Education (Simpósio Brasileiro de Informática na Educação-SBIE), volume 29, page 1113.

Chawla, K., Chiou, M., Sandes, A., and Blikstein, P. (2013). Dr. wagon: a'stretchable'toolkit for tangible computer programming. In Proceedings of the 12th international conference on interaction design and children, pages 561-564. ACM.

Hayashi, E., Posada, J. E. G., Maike, V. R., and Baranauskas, M. C. C. (2016). Exploring new formats of the self-assessment manikin in the design with children. In Proceedings of the 15th Brazilian Symposium on Human Factors in Computing Systems, page 27. ACM.

Horn, M. S., Crouser, R. J., and Bers, M. U. (2012). Tangible interaction and learning: the case for a hybrid approach. Personal and Ubiquitous Computing, 16(4):379-389.

Ishii, H. and Ullmer, B. (1997). Tangible bits: towards seamless interfaces between people, bits and atoms. In Proceedings of the ACM SIGCHI Conference on Human factors in computing systems, pages 234-241. ACM.

Kazakoff, E. R., Sullivan, A., and Bers, M. U. (2013). The effect of a classroom-based intensive robotics and programming workshop on sequencing ability in early childhood. Early Childhood Education Journal, 41(4):245-255.

Resnick, M., Martin, F., Berg, R., Borovoy, R., Colella, V., Kramer, K., and Silverman, B. (1998). Digital manipulatives: new toys to think with. In Proceedings of the SIGCHI conference on Human factors in computing systems, pages 281-287. ACM Press/Addison-Wesley Publishing Co.

Sullivan, A., Elkin, M., and Bers, M. U. (2015). Kibo robot demo: engaging young children in programming and engineering. In Proceedings of the 14th international conference on interaction design and children, pages 418-421. ACM.

Uttal, D. H., Miller, D. I., and Newcombe, N. S. (2013). Exploring and enhancing spatial thinking: Links to achievement in science, technology, engineering, and mathematics? Current Directions in Psychological Science, 22(5):367-373.

Verdine, B. N., Golinkoff, R. M., Hirsh-Pasek, K., and Newcombe, N. S. (2014). Finding the missing piece: Blocks, puzzles, and shapes fuel school readiness. Trends in Neuroscience and Education, 3(1):7-13.

Worsley, M. and Blikstein, P. (2013). Towards the development of multimodal action based assessment. In Proceedings of the third international conference on learning analytics and knowledge, pages 94-101. ACM.

Wyeth, P. and Purchase, H. C. (2003). Using developmental theories to inform the design of technology for children. In Proceedings of the 2003 conference on Interaction design and children, pages 93-100. ACM.

$\mathrm{Xu}, \mathrm{D}$. (2005). Tangible user interface for children-an overview. In Proc. of the UCLAN Department of Computing Conference.

Xu, D., Read, J. C., Sim, G., and McManus, B. (2009). Experience it, draw it, rate it: capture children's experiences with their drawings. In Proceedings of the 8th International Conference on Interaction Design and Children, pages 266-270. ACM. 